\title{
Tolerance of the photosynthetic apparatus in recombinant lines of wheat adapting to water stress of varying intensity
}

\author{
S.V. OSIPOVA, ${ }^{* * *,+}$, A.V. PERMYAKOV*, M.D. PERMYAKOVA*, E.G. RUDIKOVSKAYA*, \\ V.V. VERCHOTUROV ${ }^{* * *}$, and A.V. RUDIKOVSKY*
}

\author{
Siberian Institute of Plant Physiology and Biochemistry SB RAS, P.O. Box 317, Lermontov St., 132, \\ 664033 Irkutsk, Russia* \\ Irkutsk State University, 5, Sukhe-Bator St., 664003, Irkutsk, Russia** \\ National Research Irkutsk State Technical University, 83, Lermontov St., 664074, Irkutsk, Russia***
}

\begin{abstract}
The stress tolerance index (STI) of leaf photosynthetic parameters was analysed in recombinant introgression lines of spring wheat (Triticum aestivum L.) grown under water stress of varying intensity in the simulated conditions of soil and soil-atmospheric drought. STI for the chlorophyll content was $>1$ regardless of experimental conditions. Carotenoids content increased only when soil drought occurred. Maximum quantum yield of PSII photochemistry was the most stable and stress-resistant parameter. Minimal fluorescence yield of the dark-adapted state was only sensitive to soil-atmospheric drought. Nonphotochemical quenching decreased under water stress, while parameters of the fast light curve based on chlorophyll fluorescence increased proportionally to the level of the stress load. We believe that these parameters are the most sensitive to the changes in the water supply of wheat plants, and are convenient for the rapid and noninvasive assessment of the wheat photosynthetic apparatus state under drought conditions.
\end{abstract}

Additional key words: antioxidant enzymes; carotenoids; chlorophyll content; chlorophyll fluorescence; drought; gas exchange.

\section{Introduction}

Photosynthesis is a sophisticated multistage process involving the synthesis of complex carbohydrates from $\mathrm{CO}_{2}$. During the photo-phase of this process, water molecules donate the electrons necessary to transform $\mathrm{NADP}^{+}$into NADPH. For this reason, photosynthesis is extremely sensitive to water stress caused not only by a low soil water content, but also by the water vapour deficiency in the air. The photosynthetic response of a plant to water stress is complex and depends on the intensity and duration of the stress as well as on the water stress combined with other stress factors (Chaves et al. 2009, Ashraf and Harris 2013). The response of the photosynthetic apparatus (PA) to drought was extensively studied and different plants were considered in this respect (Ashraf and Harris 2013, Cicevan et al. 2016, Mathobo et al. 2017), including strategic agricultural crops such as wheat. For the latter, gas exchange and chlorophyll (Chl) fluorescence were shown to depend not only on environmental conditions, but also, essentially, on the genotype (variety) (Liu et al. 2006, Zivcak et al. 2008, 2013; Keyvan 2010, Lonbani and Arzani 2011, Wang et al. 2016, Li et al. 2017). The shoot biomass and leaf photosynthetic parameters were measured in recombinant introgression lines (RILs) Chinese Spring/ Synthetic 6x (CS/Syn), grown under optimal conditions of water supply and water stress of varying intensity to map quantitative trait loci (QTL) related to the functioning of PA in the genome of common wheat (Osipova et al. 2016, Permyakova et al. 2017). However, the comparative analysis of the photosynthetic parameters tolerance, observed during the period of adaptation of wheat to water

$\overline{\text { Received }} 6$ September 2017, accepted 18 May 2018.

${ }^{+}$Corresponding author; e-mail: svetlanaosipova2@mail.ru

Abbreviations: BM - shoot biomass; Chl - chlorophyll; Car - carotenoids; DM - dry mass; $E$ - transpiration rate; ETR ${ }_{160}-$ electron transport rate at $160 \mu \mathrm{mol}\left(\right.$ photon) $\mathrm{m}^{-2} \mathrm{~s}^{-1} ; \mathrm{ETR}_{\max }-$ maximum electron transport rate; $\mathrm{F}_{0}$ - minimal fluorescence yield of the darkadapted state; $F_{0}{ }^{\prime}$ - minimal fluorescence yield of the light-adapted state; $F_{m}$ - maximal fluorescence yield of the dark-adapted state; $F_{m}{ }^{\prime}$ - maximal fluorescence yield of the light-adapted state; $F_{t}$ - stationary Chl fluorescence; $F_{v} / F_{m}-$ maximum quantum yield of PSII photochemistry; $\mathrm{F}_{\mathrm{V}} / \mathrm{F}_{0}$ - the contribution of the light reactions to primary photochemistry; $g_{\mathrm{s}}$ - stomatal conductance; $1 \mathrm{k}$ - intensity of illumination, expressing the beginning of PAR saturation; NPQ - nonphotochemical quenching; $P_{\mathrm{N}}$ - net photosynthetic rate; $\mathrm{PA}$ - photosynthetic apparatus; $\mathrm{q}_{\mathrm{N}}$ - nonphotochemical quenching coefficient; RILs - recombinant introgression lines; $\mathrm{R}_{\mathrm{fd}}-$ vitality index; STI - stress tolerance index; SD - soil drought; SAD - soil-atmospheric drought; SOD - superoxide dismutase; APX - ascorbate peroxidase; DHAR - dehydroascorbate reductase; GR - glutathione reductase; TChl - total chlorophyll; WUE - water-use efficiency $\left(=P_{\mathrm{N}} / E\right) ; \Phi_{\mathrm{PSII}}-$ effective quantum yield of PSII photochemistry.

Acknowledgements: This work was financially supported by Russian Foundation for Basic Research (grant 18-04-00481). The research was carried out using the equipment of The Core Facilities Center "Bioanalitika" at The Siberian Institute of Plant Physiology and Biochemistry SB RAS (SIPPB SB RAS, Irkutsk, Russia). We express our deep gratitude to A. Börner (IPK, Gatersleben) and to T. Pshenichnikova (ICG SB RAS, Novosibirsk) for providing us with the wheat lines and the gas analyser. 
stress of different intensity, remained untouched in the published studies just cited.

A convenient noninvasive method for assessing the stability of PA including drought is based on measuring the fluorescence of $\mathrm{Chl}$. The applicability of various parameters, obtained with the help of this method (taking into account their physiological values), for rapid screening of the resistance of plants to unfavourable environmental conditions, is actively discussed in the literature (Lichtenthaler et al. 2005, Lazár 2015, Goltsev et al. 2016, Kalaji et al. 2017). The dissipation of excess light energy can occur in various ways. As a rule, the nonphotochemical quenching of fluorescence increases under stress, but Zivcak et al. (2013) showed that for winter wheat, the cyclic path of electrons around PSII and PSI is the main way how to dissipate excess energy during drought. We assumed that the fast light curve based on Chl fluorescence indicators can be the most sensitive to water stress in wheat and can serve as a convenient tool for screening wheat genotypes for drought resistance in various breeding programs. The aim of this work was a large-scale verification of this hypothesis under conditions of water stress with different intensity using a set of wheat RILs CS/Syn, which allowed analysis of the variability in responses to water stress.

\section{Materials and methods}

Plant materials and experimental conditions: In our work, we used the set of genome D RILs created by means of crossing the Chinese Spring wheat and the synthetic hexaploid Synthetic 6x (Pestsova et al. 2006). Each line carried a certain area of introgression from the wild grass of Aegilops tauschii Coss on the genetic background of the selection wheat, Chinese Spring. Thus, RILs allowed studying the variability of photosynthetic parameters in genetically closely related genotypes. In order to reveal the dependence of photosynthetic parameters on the level of stress load, two growth regimes were chosen, which we took as independent experiments. During the first independent experiment, 71 lines were grown in the greenhouse of Siberian Institute of Plant Physiology and Biochemistry, Siberian Branch of the Russian Academy of Sciences (SIPPB SB RAS) under a 16-h photoperiod under conditions of natural daylight with a 2 -h illumination in the morning and in the evening at around $600 \mu \mathrm{mol}$ (photon) $\mathrm{m}^{-2} \mathrm{~s}^{-1}$. Temperature fluctuations were $21 / 15^{\circ} \mathrm{C}$, and the ones of relative air humidity were about $20 / 30 \%$ during day/night. During the second independent experiment, 79 lines were grown under controlled conditions in a climatic chamber CLF Plant Master (CLF Plant Climatic $G M B H$, Wertingen, Germany), and a 16-h photoperiod was maintained at $600 \mu \mathrm{mol}$ (photon) $\mathrm{m}^{-2} \mathrm{~s}^{-1}$. Temperature fluctuations were $23 / 16^{\circ} \mathrm{C}$ during day/night and the relative air humidity was $60 \%$. In each experiment, the plants were grown in a 1:1:1 of humus:sand:peat mixture and two variants of water supply were used - an optimal one and one of water stress. In one pot, the plants were kept wellwatered, while in the other pot, water was withheld from the three-leaf stages until the soil moisture content had fallen to $30 \%$ of saturation. The moisture content of the soil for the well-watered control plants was maintained at $60 \%$ saturation. Soil moisture status was monitored three times per week by weighing the pots, and adjusted when necessary. The conditions of the first independent experiment were distinguished by a low air humidity, and a water stress variant in this case was indicated as soil-atmospheric drought (SAD), while in the second experiment it was identified as soil drought (SD). Twentyfour hours after the Chl fluorescence was measured, flag leaf material was frozen with liquid nitrogen and was kept at $-70^{\circ} \mathrm{C}$ until the time of the analysis of $\mathrm{Chl}$ and carotenoids (Car) contents.

Chl and Car contents: A 50-mg aliquot of frozen flag leaf tissue was homogenized in $3 \mathrm{~mL}$ of $80 \%$ acetone with $10 \mathrm{mg}$ of $\mathrm{CaCO}_{3}$. The homogenate was made up to 10 $\mathrm{mL}$ with $80 \%$ acetone, then centrifuged at $2,000 \times g$ for $10 \mathrm{~min}$. A $3-\mathrm{mL}$ aliquot of the supernatant was used to measure absorbance at 440.5, 648, and $664 \mathrm{~nm}$ using a Hitachi U-1100 spectrophotometer (Hitachi Ltd., Tokyo, Japan). The contents of Chl $a$, Chl $b$, Chl $(a+b)$, and Car were calculated according to the extinction coefficients given by Wettstein (1957). Pigment contents were expressed as pigment contents per gram dry mass of leaves $\left[\mathrm{mg} \mathrm{g}^{-1}(\mathrm{DM})\right]$.

Enzymeactivities:UnderconditionsofSD, activities ofafew enzymes of the water-water cycle were measured, namely: superoxide dismutase (SOD, EC 1.15.1.1), ascorbate peroxidase (APX, EC 1.11.1.11), dehydroascorbate reductase (DHAR, EC 1.8.5.1), and glutathione reductase (GR, EC 1.6.4.2). Enzyme extracts were prepared as described by Osipova et al. (2016). Peak activities of DHAR, APX, and GR were determined in batches of three extracts, which were introduced into a flat-bottomed UV-Star microplate (Greiner Bio-One GmbH, Frickenhausen, Germany); reading were taken using an Infinite M200 PRO microplate reader (Tecan Group Ltd., Männedorf, Switzerland). Reaction mixtures $(200 \mu \mathrm{L})$ contained $10 \mu \mathrm{L}$ of the enzyme extract in all experiments. DHAR was assayed in $50 \mathrm{mM}$ potassium phosphate buffer, $\mathrm{pH}$ 7.0, $0.2 \mathrm{mM}$ dehydroascorbate (Sigma-Aldrich, USA), and $2.5 \mathrm{mM}$ reduced glutathione (Reanal Private Ltd., Budapest, Hungary), and its activity was followed by an increase in $\mathrm{A}_{265}$ for $1 \mathrm{~min}$ (extinction coefficient, $14 \mathrm{mM}^{-1}$ $\mathrm{cm}^{-1}$ ) (Baier et al. 2000). GR activity was determined by following the oxidation of NADPH at $340 \mathrm{~nm}$ for $1 \mathrm{~min}$ (extinction coefficient of $6.2 \mathrm{mM}^{-1} \mathrm{~cm}^{-1}$ ) in $50 \mathrm{mM}$ potassium phosphate buffer, $\mathrm{pH} 7.8$, containing $0.10 \mathrm{mM}$ NADPH (Sigma Aldrich, USA), and $1 \mathrm{mM}$ of oxidized glutathione (Reanal Private Ltd., Budapest, Hungary) (de Lamotte 2000). APX activity was determined by following the decrease in $\mathrm{A}_{290}$ of an assay mixture containing $50 \mathrm{mM}$ potassium phosphate buffer, $\mathrm{pH} 7.0,0.5 \mathrm{mM}$ ascorbic acid (Sigma Aldrich, USA) and $0.1 \mathrm{mM} \mathrm{H}_{2} \mathrm{O}_{2}$ (extinction coefficient, $2.8 \mathrm{mM}^{-1} \mathrm{~cm}^{-1}$ ) (Nakano and Asada 1981). Enzymatic activity was expressed as micromoles of substrate per milligram of protein per min at $25^{\circ} \mathrm{C}$. Total SOD activity was measured spectrophotometrically 
using an Infinite M200 PRO microplate reader and flatbottomed Citotest microplate (www.citotest.com) based on the inhibition of nitroblue tetrazolium (NBT) reduction, following Giannopolitis and Ries (1977). Each 200- $\mu \mathrm{L}$ reaction contained $50 \mathrm{mM}$ potassium phosphate buffer $(\mathrm{pH}$ 7.8), 13 mM methionine (Reanal Private Ltd., Budapest, Hungary), $2 \mu \mathrm{M}$ riboflavin (Reanal Private Ltd., Budapest, Hungary), $63 \mu \mathrm{M}$ NBT (Sigma Aldrich, USA), $0.1 \mu \mathrm{M}$ EDTA, and $10 \mu \mathrm{L}$ of the extract. A unit of SOD (U) was defined as the quantity required to inhibit the reduction of NBT by $50 \%$. Specific enzymatic activity was calculated as $\mathrm{U} \mathrm{mg} \mathrm{mg}^{-1}$ (protein). Protein content was determined according to Bradford, using BSA (Sigma Aldrich, USA) as a standard.

Gas exchange and $\mathrm{Chl}$ fluorescence: In each line, the parameters of gas exchange and Chl fluorescence were measured in the middle part of the fully-developed flag leaves at the stage of stalking. Since different lines reached the desired stage non-simultaneously, all measurements were taken within two weeks. Stomatal conductance $\left(g_{\mathrm{s}}\right)$, transpiration $(E)$, and net photosynthetic rate $\left(P_{\mathrm{N}}\right)$ were measured using a portable gas-exchange system (LCi Photosynthesis System, ADC BioScientific Ltd., Hoddesdon, England). Water-use efficiency (WUE) was calculated as $P_{\mathrm{N}} / E$. The measurements of the Chl fluorescence of leaves were carried out using a portable impulse fluorometer PAM-2500 (Walz, Effelrich, Germany). In order to register the minimal fluorescence yield of the dark-adapted state $\left(\mathrm{F}_{0}\right)$, we darkened the leaves for $30 \mathrm{~min}$ and then illuminated them with modulated measuring light of low frequency $(5 \mathrm{~Hz})$ and low intensity $(630 \mathrm{~nm})$. The intensity of the $\mathrm{Chl}$ fluorescence under conditions of closed reactive centers $\left(\mathrm{F}_{\mathrm{m}}\right)$ was measured after the exposure of a light impulse of high intensity $[25,000 \mu \mathrm{mol}($ photon) $\left.\mathrm{m}^{-2} \mathrm{~s}^{-1}, 630 \mathrm{~nm}\right]$. In addition, we calculated the relative rate of electron transport (ETR) provided by PSII, and the effective photochemical quantum yield of PSII ( $\left.\Phi_{\text {PSII }}\right)$ in the light-adapted state. In order to do this, we carried out the registration of changes in the $\mathrm{Chl}$ fluorescence indices observed under the influence of actinic red light exposure $160 \mu$ mol(photon) $\mathrm{m}^{-2} \mathrm{~s}^{-1}$, maintaining photosynthesis. Parameters $1 \mathrm{k}$ and $\mathrm{ETR}_{\max }$ were calculated from the $\mathrm{Chl}$ fluorescence light curve [PAR range from 0 to 2,000 $\mu \mathrm{mol}\left(\right.$ photon) $\mathrm{m}^{-2} \mathrm{~s}^{-1}$. Measured and calculated $\mathrm{Chl}$ fluorescence parameters used in our work are presented in the text table bellow.

Stress tolerance index (STI) as defined by Fernandez (1993) was calculated for all the parameters according to the formula $\mathrm{STI}=\mathrm{T}_{\mathrm{d}} \times \mathrm{T}_{\mathrm{c}} / \mathrm{T}^{2}$, where $\mathrm{T}_{\mathrm{d}}$ and $\mathrm{T}_{\mathrm{c}}$ are values of the attributes under drought conditions and in the control for each genotype, and $T_{c}$ is the average value of the attribute under controlled conditions for all the genotypes.

Statistical analyses: The main shoot biomass was represented as the average of $8-10$ plants per line. In our study, one plant was taken for biological replication. The $g_{\mathrm{s}}, E$, and $P_{\mathrm{N}}$ were averages of eight biological replicates. Chl fluorescence was measured on the flag leaves of four plants per line. Pigment contents were averages of three biological replicates, each consisting of three analytical replicates. The enzymes activity was measured in three biological replicates, each being run in triplicate. SigmaPlot v.12.0 (Systat Software, Inc., San Jose California, USA, www.sigmaplot.com) was used to calculate means, standard deviations and Spearman correlations as well as to perform $t$-tests.

\section{Results}

The response of the PA of wheat RILs under conditions of adaptation to SD and SAD: As can be seen from the spider plot (average values of the attributes in percentage under water stress) photosynthesis was limited, mainly by stomatal effects, regardless of the experimental conditions (Fig.1A,B; Tables 1S, 2S - supplements). Average values of $g_{\mathrm{s}}, E$, and $P_{\mathrm{N}}$ decreased virtually to the same extent both under SD and SAD conditions compared with the control. Biomass, on the average, was better preserved when the plants were grown in the climatic chamber at an air humidity of $60 \%$. The Chl content approximately equally increased compared with the control under SD and SAD conditions. The plants response to various growing conditions was different in average values of the Car content. Thus, under SAD conditions, the Car content slightly decreased, while under SD conditions, on the contrary, it increased compared with the control, and for this reason, TChl/Car ratio was significantly higher under severe drought. Among parameters of the Chl fluorescence, $\mathrm{F}_{\mathrm{v}} / \mathrm{F}_{\mathrm{m}}, \mathrm{F}_{\mathrm{m}} / \mathrm{F}_{0}$, and $\mathrm{F}_{\mathrm{v}} / \mathrm{F}_{0}$ were the most stable ones. Under

$\begin{array}{ll}\mathrm{F}_{0} & \text { Minimum Chl fluorescence from a dark-adapted leaf (PSII centers open) } \\ \mathrm{F}_{\mathrm{m}} & \text { Maximum Chl fluorescence from a dark-adapted leaf (PSII centers closed) } \\ \mathrm{F}_{\mathrm{v}}=\mathrm{F}_{\mathrm{m}}-\mathrm{F}_{0} & \text { Maximum variable Chl fluorescence from a dark-adapted leaf } \\ \mathrm{F}_{\mathrm{t}} & \text { Stationary Chl fluorescence } \\ \mathrm{R}_{\mathrm{fd}}=\left[\mathrm{F}_{\mathrm{m}}-\mathrm{F}_{\mathrm{t}}\right] \mathrm{F}_{\mathrm{t}} & \text { Vitality index (Lichtenthaler } \text { et al. 2005) } \\ \mathrm{F}_{\mathrm{v}} / \mathrm{F}_{\mathrm{m}}=\left[\mathrm{F}_{\mathrm{m}}-\mathrm{F}_{0}\right] / \mathrm{F}_{\mathrm{m}} & \text { Maximum quantum yield of PSII photochemistry } \\ \mathrm{F}_{\mathrm{v}} / \mathrm{F}_{0} & \text { The contribution of the light reactions to primary photochemistry } \\ \Phi_{\mathrm{PSII}}=\mathrm{F}_{\mathrm{m}}{ }^{\prime}-\mathrm{F}_{\mathrm{t}} / \mathrm{F}_{\mathrm{m}}{ }^{\prime} & \text { Effective photochemical quantum yield of PSII } \\ \mathrm{NPQ}=\left[\mathrm{F}_{\mathrm{m}} / \mathrm{F}_{\mathrm{m}}{ }^{\prime}\right]-1 & \text { Nonphotochemical quenching of chlorophyll fluorescence } \\ \mathrm{q}_{\mathrm{N}}=1-\left[\mathrm{F}_{\mathrm{m}}{ }^{\prime}-\mathrm{F}_{0}{ }^{\prime}\right] /\left[\mathrm{F}_{\mathrm{m}}-\mathrm{F}_{0}\right] & \text { Coefficient of nonphotochemical fluorescence quenching } \\ \mathrm{ETR}_{160} & \text { Electron transport rate at } 160 \mu \text { mol(photon) } \mathrm{m}^{-2} \mathrm{~s}^{-1} \\ \mathrm{ETR}_{\max } & \text { Maximum electron transport rate, } \mu \text { mol(electron) } \mathrm{m}^{-2} \mathrm{~s}^{-1} \\ \mathrm{lk} & \text { Intensity of illumination, expressing the beginning of PAR }\end{array}$



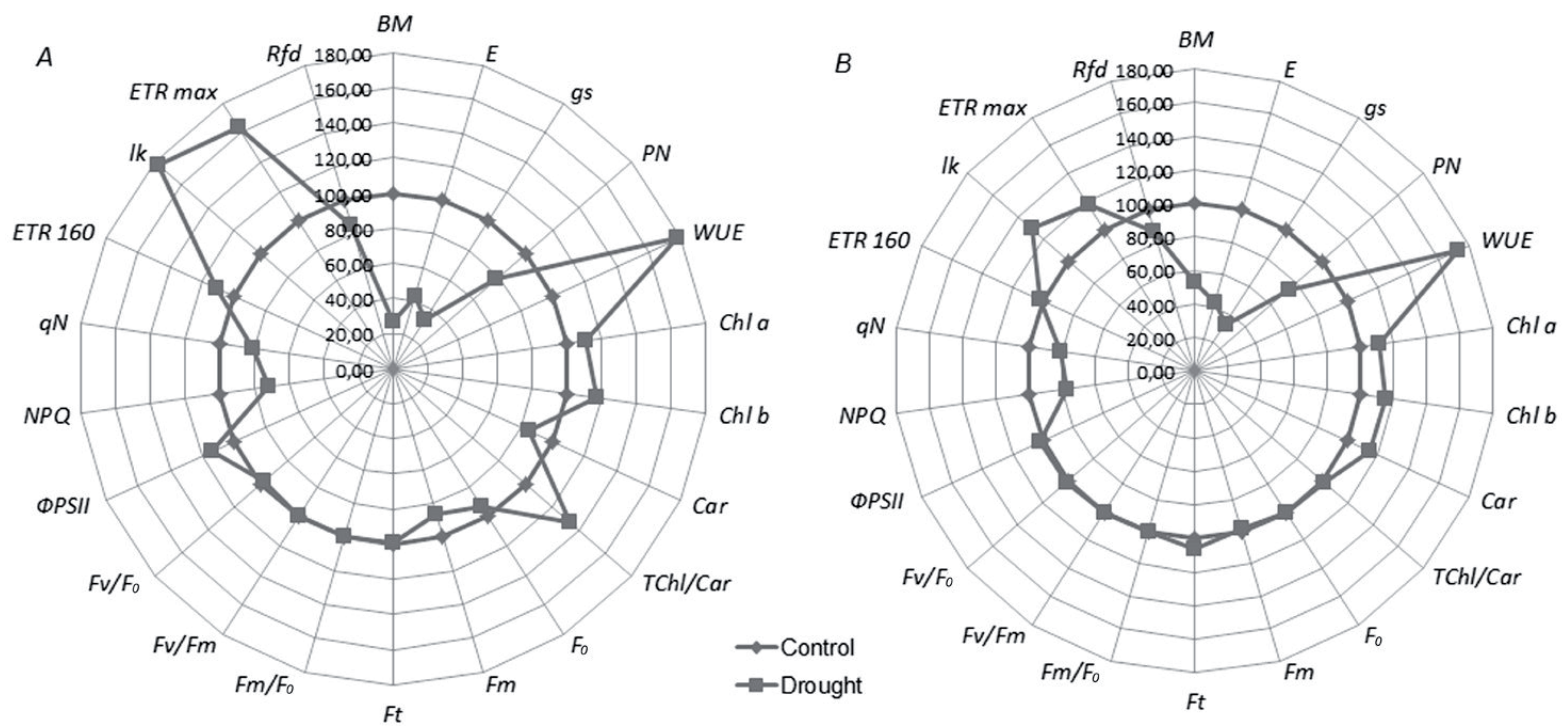

Fig 1. Spider plot shows the relative standard deviation (in \%) of the average values of the studied parameters in CS/Syn RILs, which are observed under conditions of soil-atmospheric $(A, n=71)$ and soil $(B, n=79)$ drought, from the control values of the parameters under optimal watering conditions (control - 100\%). BM - shoot biomass; Chl - chlorophyll; Car - carotenoids; ETR 160 - electron transport rate at $160 \mu \mathrm{mol}\left(\right.$ photon) $\mathrm{m}^{-2} \mathrm{~s}^{-1} ; \mathrm{ETR}_{\max }$ - maximum electron transport rate; $\mathrm{F}_{0}$ - minimal fluorescence yield of the dark-adapted state; $F_{m}-$ maximal fluorescence yield of the dark-adapted state; $F_{t}-$ stationary Chl fluorescence; $F_{v} / F_{m}-$ maximum quantum yield of PSII photochemistry; $\mathrm{F}_{\mathrm{v}} / \mathrm{F}_{0}$ - the contribution of the light reactions to primary photochemistry; $g_{\mathrm{s}}$ - stomatal conductance; $1 \mathrm{k}$ - intensity of illumination, expressing the beginning of PAR saturation; NPQ - nonphotochemical quenching; $P_{\mathrm{N}}-$ net photosynthetic rate; $\mathrm{q}_{\mathrm{N}}-$ nonphotochemical quenching coefficient; Rfd - vitality index; TChl - total chlorophyll; WUE - water-use efficiency $\left(=P_{\mathrm{N}} / E\right)$; $\Phi_{\mathrm{PSII}}$ - effective quantum yield of PSII photochemistry.

SAD conditions, $F_{m}$ decreased significantly when $\Phi_{\text {PSII }}$ increased, while under SD conditions, these parameters remained unchanged. The parameters of the fast light curve based on Chl fluorescence - $1 \mathrm{k}$ and $\mathrm{ETR}_{\max }$ - increased 1.7 times on average under SAD, and 1.2 times under SD. The average values of the parameters, characterizing nonphotochemical fluorescence quenching (NPQ and $\mathrm{q}_{\mathrm{N}}$ ), decreased under stress regardless of the experiment and approximately to the same extent (Fig. $1 A, B$; Tables $1 \mathrm{~S}, 2 \mathrm{~S}$ ).

For a quantitative comparison of PA response to soil and soil-atmospheric water stress, we carried out the analysis of differences between average values of the STI defined by Fernandez (1993). The index was calculated for all the studied attributes in the two independent experiments (Table 1; Tables 3S, 4S - supplements). The wide range of changes in STI observed virtually in all the attributes is indicative of the fact that different lines responded differently to the stress conditions of different intensity. STI for the parameters of gas exchange $\left(E, g_{\mathrm{s}}\right.$, $P_{\mathrm{N}}$, WUE) of the chlorophyll fluorescence rapid light curve (lk and $\mathrm{ETR}_{\max }$ ) and of NPQ was highly variable in two independent experiments. Additionally, under SAD, STI was significantly different for $F_{0}, F_{m}$, and $F_{t}$. Biomass and Car were much more tolerant to SD conditions. Under $\mathrm{SAD}$, the average STI values for $\mathrm{F}_{0}, \Phi_{\mathrm{PSII}}, \mathrm{ETR}_{160}, \mathrm{ETR}_{\max }$, and $1 \mathrm{k}$ were significantly higher. The average $\mathrm{STI}$ values for $F_{v} / F_{m}, F_{v} / F_{0}, F_{m} / F_{0}, R_{f d}$, as well as for NPQ and $q_{N}$, remained the same under different water stress intensities.
Under the conditions of soil drought, we identified five lines - 1D 4, 1D 6, 2D 16, 7D 3, and 7D 1b as the most resistant. These lines were characterized by a relatively high stability of the shoot mass (average STI $=0.85$ ) and of the content of photosynthetic pigments (average STI = 1.3-1.5). The average STI values for $1 \mathrm{k}$ and $\mathrm{ETR}_{\max }$ in these lines varied around 1 . Under more severe conditions of $\mathrm{SAD}$, the line 1D 6 (Tables 3S, 4S) was the most resistant in terms of shoot mass from these five lines.

The interrelation between average STI values for the attributes: Under SAD conditions, STI for the biomass correlated positively with the STI for WUE, ETR 160 , and $1 \mathrm{k}$, and negatively with STI for $E, g_{\mathrm{s}}, \mathrm{F}_{0}, \mathrm{~F}_{\mathrm{m}}, \mathrm{F}_{\mathrm{t}}$, and $\Phi_{\text {PSII }}$ (Table 2). STI for $P_{\mathrm{N}}$ and WUE positively correlated with STI for lk. The negative correlation of STI for pigments content with STI for $F_{0}, F_{m}$, and $F_{t}$ could be observed. STI for TChl/Car positively correlated with the STI for $\mathrm{F}_{0}$. Under SAD, STI for $\Phi_{\text {PSII }}$ correlated positively with STI for $\mathrm{F}_{0}, \mathrm{~F}_{\mathrm{m}}, \mathrm{F}_{\mathrm{t}}, \mathrm{F}_{\mathrm{v}} / \mathrm{F}_{\mathrm{m}}, \mathrm{F}_{\mathrm{v}} / \mathrm{F}_{0}, \mathrm{ETR}_{160}, \mathrm{ETR}_{\max }$, and $\mathrm{lk}$, and negatively with STI for NPQ and $\mathrm{q}_{\mathrm{N}}$. STI for NPQ and $\mathrm{q}_{\mathrm{N}}$ correlated positively with STI for $E$ and $g_{\mathrm{s}}$, and negatively with STI for $F_{0}, F_{m}, F_{t}$, and $F_{v} / F_{m}$. Under the same conditions, $\mathrm{STI}$ for $\mathrm{R}_{\mathrm{fd}}$ positively correlated with STI for $E$ and $g_{\mathrm{s}}$, as well as with STI for NPQ and $\mathrm{q}_{\mathrm{N}}$. Finally, STI for $\mathrm{R}_{\mathrm{fd}}$ correlated negatively with STI for biomass, WUE, ETR ${ }_{160}$, lk, and ETR $_{\max }$.

Quite a different nature of correlating relationships 
Table 1. Average values and the range of variation in the stress tolerance index (STI) for shoot biomass, photosynthetic pigment contents, gas-exchange and Chl fluorescence parameters. BM - shoot biomass; Chl - chlorophyll; Car - carotenoids; ETR 160 - electron transport rate at $160 \mu \mathrm{mol}\left(\right.$ photon) $\mathrm{m}^{-2} \mathrm{~s}^{-1} ; \mathrm{ETR}_{\max }$ - maximum electron transport rate; $\mathrm{F}_{0}$ - minimal fluorescence yield of the darkadapted state; $F_{m}$ - maximal fluorescence yield of the dark-adapted state; $F_{t}-$ stationary Chl fluorescence; $F_{v} / F_{m}-$ maximum quantum yield of PSII photochemistry; $\mathrm{F}_{\mathrm{V}} / \mathrm{F}_{0}$ - the contribution of the light reactions to primary photochemistry; $g_{\mathrm{s}}$ - stomatal conductance; $\mathrm{lk}$ - intensity of illumination, expressing the beginning of PAR saturation; NPQ - nonphotochemical quenching; $P_{\mathrm{N}}-$ net photosynthetic rate; $\mathrm{q}_{\mathrm{N}}-$ nonphotochemical quenching coefficient; $\mathrm{R}_{\mathrm{fd}}-$ vitality index; TChl - total chlorophyll; WUE - water-use efficiency $\left(=P_{\mathrm{N}} / E\right)$; $\Phi_{\text {PSII }}$ - effective quantum yield of PSII photochemistry. ${ }^{* *}$ - significant at $p<0.01,{ }^{* * *}$ - at $p<0.001,{ }^{* * * *}-$ at $p<0.0001$. Comparisons were made for STI values under different growing conditions. V - the coefficient of variation.

\begin{tabular}{lllllll}
\hline Traits & Greenhouse & & 5 & \multicolumn{2}{l}{ Climatic chamber CLF PlantMaster } \\
& SAD, $n=71$ & & & SD, $n=79$ \\
& Mean $\pm \mathrm{SE}$ & Min-Max & $\mathrm{V}, \%$ & Mean $\pm \mathrm{SE}$ & Min - Max & $\mathrm{V}, \%$ \\
\hline $\mathrm{BM}$ & $0.3 \pm 0.1$ & $0.1-0.4$ & 36 & $0.5 \pm 0.1^{* * *}$ & $0.2-1.1$ & 26 \\
$\mathrm{Chl} a$ & $1.1 \pm 0.3$ & $0.6-1.9$ & 25 & $1.1 \pm 0.3$ & $0.6-1.9$ & 25 \\
$\mathrm{Chl} b$ & $1.2 \pm 0.3$ & $0.7-2.0$ & 23 & $1.1 \pm 0.4$ & $0.3-2.2$ & 32 \\
$\mathrm{Car}$ & $0.9 \pm 0.2$ & $0.4-1.6$ & 27 & $1.1 \pm 0.2^{* * * *}$ & $0.5-2.0$ & 21 \\
$\mathrm{TChl} / \mathrm{Car}$ & $1.3 \pm 0.2$ & $0.9-2.0$ & 17 & $1.0 \pm 0.2^{* * * *}$ & $0.5-1.5$ & 16 \\
$\mathrm{E}$ & $0.4 \pm 0.2$ & $0.1-1.2$ & 44 & $0.4 \pm 0.3$ & $01-1.1$ & 58 \\
$g_{\mathrm{s}}$ & $0.4 \pm 0.2$ & $0.1-1.0$ & 61 & $0.3 \pm 0.2$ & $0.04-0.9$ & 74 \\
$P_{\mathrm{N}}$ & $0.9 \pm 0.8$ & $0.1-5.2$ & 94 & $0.8 \pm 0.6$ & $0.4-2.7$ & 75 \\
$\mathrm{WUE}$ & $2.0 \pm 1.2$ & $0.4-6.7$ & 78 & $1.7 \pm 1.1$ & $0.4-4.8$ & 62 \\
$\mathrm{~F}_{0}$ & $1.4 \pm 0.6$ & $0.7-3.2$ & 44 & $1.0 \pm 0.2^{* * *}$ & $0.6-1.6$ & 15 \\
$\mathrm{~F}_{\mathrm{m}}$ & $0.9 \pm 0.4$ & $0.4-2.4$ & 49 & $1.0 \pm 0.1$ & $0.5-1.2$ & 15 \\
$\mathrm{~F}_{\mathrm{t}}$ & $1.2 \pm 0.5$ & $0.5-3.0$ & 47 & $1.3 \pm 0.3$ & $0.6-2.0$ & 22 \\
$\mathrm{~F}_{\mathrm{m}} / \mathrm{F}_{0}$ & $1.0 \pm 0.2$ & $0.7-1.4$ & 18 & $1.0 \pm 0.2$ & $0.6-1.3$ & 15 \\
$\mathrm{~F}_{\mathrm{v}} / \mathrm{F}_{0}$ & $1.0 \pm 0.2$ & $0.6-1.3$ & 18 & $1.0 \pm 0.2$ & $0.5-1.7$ & 23 \\
$\mathrm{~F}_{\mathrm{v}} / \mathrm{F}_{\mathrm{m}}$ & $1.0 \pm 1.0$ & $0.9-1.1$ & 4 & $1.0 \pm 0.1$ & $0.8-1.1$ & 5 \\
$\Phi_{\mathrm{PSII}}$ & $1.1 \pm 0.2$ & $0.7-1.8$ & 22 & $1.0 \pm 0.2^{* *}$ & $0.3-1.3$ & 19 \\
$\mathrm{NPQ}$ & $0.7 \pm 0.3$ & $0.3-1.6$ & 38 & $0.8 \pm 0.6$ & $0.4-4.6$ & 66 \\
$\mathrm{q}_{\mathrm{N}}$ & $0.8 \pm 0.2$ & $0.4-1.5$ & 27 & $0.8 \pm 0.2$ & $0.4-1.4$ & 25 \\
$\mathrm{ETR}_{160}$ & $1.1 \pm 0.3$ & $0.6-1.7$ & 22 & $1.0 \pm 0.2^{* *}$ & $0.5-1.3$ & 18 \\
$\mathrm{lk}_{\mathrm{k}}$ & $1.8 \pm 1.1$ & $0.2-6.2$ & 62 & $1.3 \pm 0.7^{* *}$ & $0.3-3.4$ & 53 \\
$\mathrm{ETR}_{\max }$ & $1.7 \pm 0.3$ & $0.5-3.7$ & 49 & $1.2 \pm 0.5^{* * *}$ & $0.3-2.4$ & 44 \\
$\mathrm{R}_{\mathrm{fd}}$ & $0.9 \pm 0.2$ & $0.5-1.3$ & 19 & $0.8 \pm 0.2$ & $0.5-1.5$ & 20 \\
\hline
\end{tabular}

between the STI for the studied attributes was observed under conditions of SD (Table 3). Thus, STI for the biomass correlated positively with STI for the photosynthetic pigments content, $F_{m}, F_{t}, F_{v} / F_{0}, F_{v} / F_{m}$, and negatively with STI for ETR $_{160}$. STI for $P_{N}$ and WUE correlated positively with STI for $\Phi_{\text {PSII }}$ and $E_{16}$, and negatively with NPQ and $\mathrm{q}_{\mathrm{N}}$. Under SD conditions, STI for Chl $a, \mathrm{Chl} b$, and TChl/ Car positively correlated with STI for $\mathrm{F}_{\mathrm{m}}, \mathrm{F}_{\mathrm{t}}, \mathrm{F}_{\mathrm{v}} / \mathrm{F}_{0}, \mathrm{~F}_{\mathrm{v}} / \mathrm{F}_{\mathrm{m}}$, and $\mathrm{ETR}_{\text {max. }}$ STI for $\mathrm{F}_{0}, \mathrm{~F}_{\mathrm{m}}$, and $\mathrm{F}_{\mathrm{t}}$ negatively correlated with STI for $\Phi_{\text {PSII }}, \mathrm{ETR}_{160}$, and $\mathrm{ETR}_{\max }$. Correlation relationships between STI for $\Phi_{\text {PSII }}$ and STI for NPQ and $\mathrm{q}_{\mathrm{N}}$ were negative, as they were under SAD conditions. Under SD, the profile of correlations between STI for $\mathrm{R}_{\mathrm{fd}}$ and the one for all the studied parameters was remarkably different. STI for $R_{\mathrm{fd}}$ correlated positively with STI for $\Phi_{\mathrm{PSII}}, \mathrm{q}_{\mathrm{N}}$, $\mathrm{lk}, \mathrm{ETR}_{160}$, and $\mathrm{ETR}_{\max }$, and negatively with STI for $\mathrm{F}_{0}$, $\mathrm{F}_{\mathrm{m}}$, and $\mathrm{F}_{\mathrm{t}}$. Both in the first and in the second independent experiment, no significant correlation between $\mathrm{STI}$ for $\mathrm{R}_{\mathrm{fd}}$ and STI for $P_{\mathrm{N}}$ was found.

Under conditions of the climatic chamber CLF PlantMaster, the activities of a few enzymes of the waterwater cycle were measured, and remarkable positive correlation relationships between STI for the activity of APX, DHAR, GR, and STI for the biomass were identified. STI for all of the four studied activities positively correlated with STI for $P_{\mathrm{N}}$, and STI for SOD and DHAR positively correlated with STI for $\Phi_{\mathrm{PSII}}$ and ETR. STI for SOD positively correlated with STI for $\mathrm{R}_{\mathrm{fd}}$ (Table 4 ).

\section{Discussion}

Stress tolerance index as defined by Fernandez (1993) is considered a good tool to evaluate the genotype tolerance based on the morphometric features and yield components in breeding programs (Naghavi et al. 2013, Ali and ElSadek 2016). STI allows us to quantify changes in a parameter of a specific genotype relatively to the average level of this parameter in the group of genotypes. We chose this index as the most relevant one for the analysis of the photosynthetic parameters tolerance in the set of CS/ Syn RILs depending on the stress intensity. Despite the significant variability of STI for most studied parameters, average values of this index allowed us to analyze the main tendencies of changes in the attributes under water 


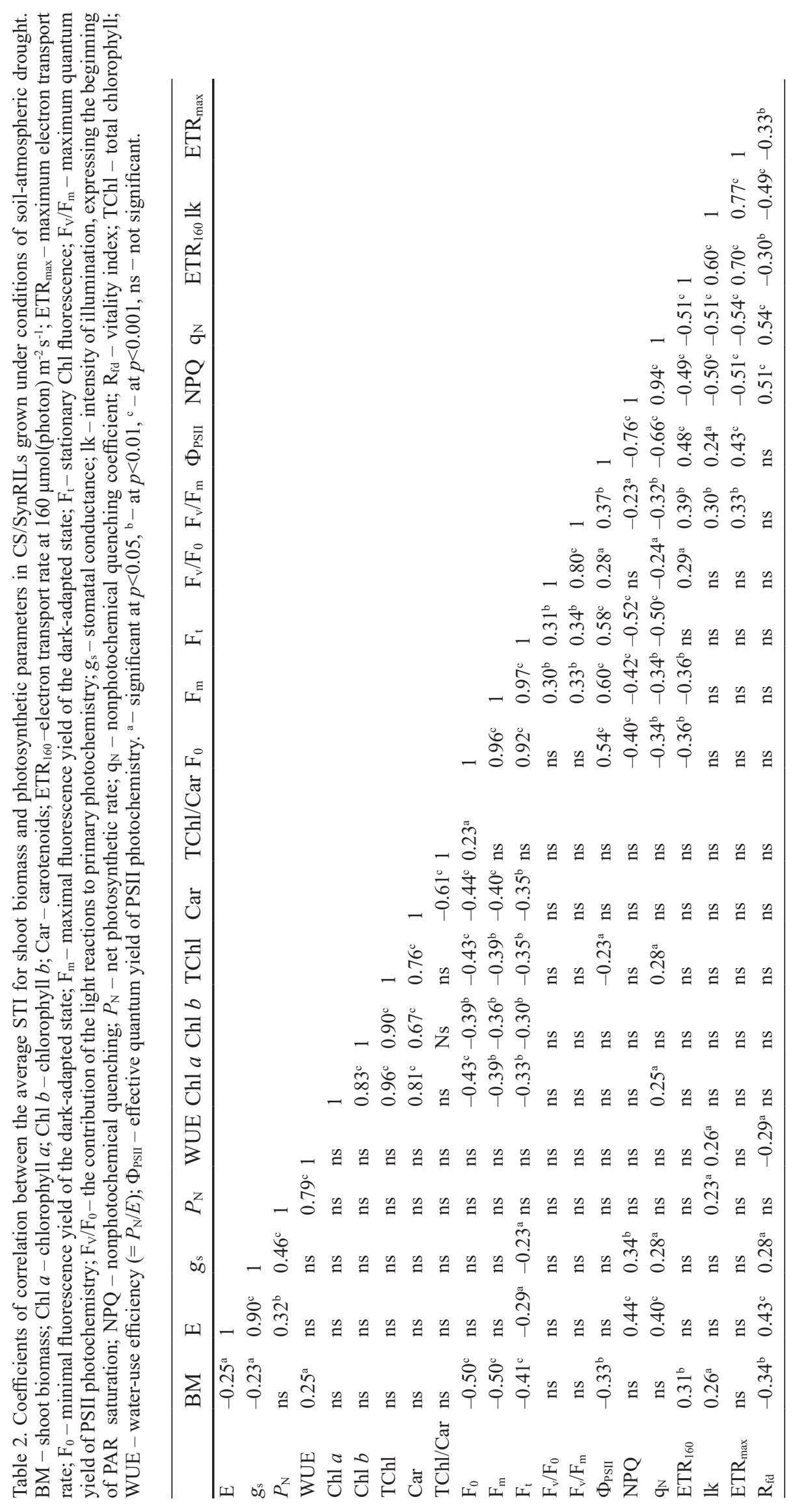




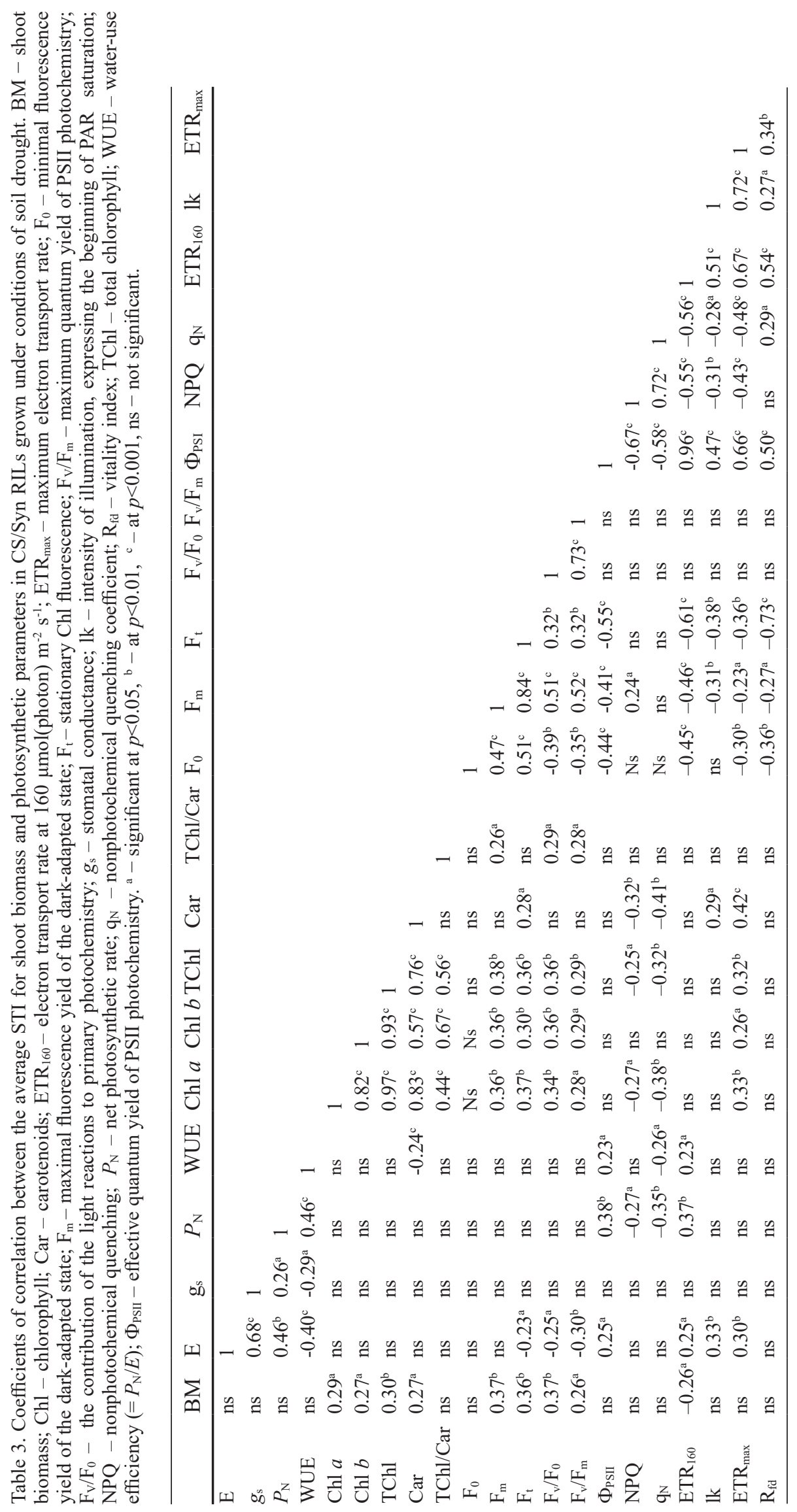


Table 4. Correlations between the average STI for the activity of the enzymes of the water-water cycle and STI for biomass and photosynthetic parameters in CS/Syn RILs, grown under soil drought conditions. APX - ascorbate peroxidase; BM shoot biomass; Chl - chlorophyll; Car - carotenoids; DHAR dehydroascorbate reductase; $\mathrm{ETR}_{160}$ - electron transport rate at $160 \mu \mathrm{mol}$ (photon) $\mathrm{m}^{-2} \mathrm{~s}^{-1}$; ETR $_{\max }-$ maximum electron transport rate; $\mathrm{F}_{0}$ - minimal fluorescence yield of the dark-adapted state; $\mathrm{F}_{\mathrm{m}}$ - maximal fluorescence yield of the dark-adapted state; $\mathrm{F}_{\mathrm{t}}-$ stationary $\mathrm{Chl}$ fluorescence; $\mathrm{F}_{\mathrm{v}} / \mathrm{F}_{\mathrm{m}}-$ maximum quantum yield of PSII photochemistry; $\mathrm{F}_{\mathrm{v}} / \mathrm{F}_{0}-$ the contribution of the light reactions to primary photochemistry; GR - glutathione reductase; $g_{s}$ - stomatal conductance; lk - intensity of illumination, expressing the beginning of PAR saturation; NPQ nonphotochemical quenching; $P_{\mathrm{N}}-$ net photosynthetic rate; $\mathrm{q}_{\mathrm{N}}$ - nonphotochemical quenching coefficient; $\mathrm{R}_{\mathrm{fd}}$ - vitality index; SOD - superoxide dismutase; STI - glutathione reductase; TChl - total chlorophyll; WUE - water-use efficiency $\left(=P_{\mathrm{N}} / E\right)$; $\Phi_{\text {PSII }}$ - effective quantum yield of PSII photochemistry. a significant at $p<0.05,{ }^{\mathrm{b}}-$ at $p<0.01,{ }^{\mathrm{c}}-$ at $p<0.001$, ns - not significant.

\begin{tabular}{|c|c|c|c|c|}
\hline STI & SOD & APX & DHAR & GR \\
\hline$\overline{\mathrm{BM}}$ & ns & $0.28^{\mathrm{a}}$ & $0.23^{\mathrm{a}}$ & $0.24^{\mathrm{a}}$ \\
\hline $\mathrm{E}$ & $0.24^{\mathrm{a}}$ & ns & ns & $-0.20^{\mathrm{a}}$ \\
\hline$g_{\mathrm{s}}$ & ns & ns & ns & ns \\
\hline$P_{\mathrm{N}}$ & $0.34^{b}$ & $0.41^{\mathrm{c}}$ & $0.23^{\mathrm{a}}$ & $0.32^{\mathrm{b}}$ \\
\hline WUE & ns & ns & ns & $0.39^{\mathrm{b}}$ \\
\hline Chl $a$ & $\mathrm{~ns}$ & ns & ns & $0.27^{\mathrm{a}}$ \\
\hline Chl $b$ & $\mathrm{~ns}$ & ns & ns & ns \\
\hline TChl & ns & ns & ns & $0.23^{\mathrm{a}}$ \\
\hline Car & ns & ns & ns & ns \\
\hline TChl/Car & $\mathrm{ns}$ & $0.26^{\mathrm{a}}$ & ns & $0.33^{\mathrm{b}}$ \\
\hline $\mathrm{F}_{0}$ & ns & ns & ns & ns \\
\hline$F_{M}$ & $-0.42^{\mathrm{c}}$ & ns & ns & ns \\
\hline $\mathrm{Ft}$ & $-0.48^{\mathrm{c}}$ & ns & ns & ns \\
\hline $\mathrm{F}_{\mathrm{v}} / \mathrm{F}_{0}$ & $-0.31^{\mathrm{b}}$ & ns & ns & ns \\
\hline $\mathrm{F}_{\mathrm{v}} / \mathrm{F}_{\mathrm{m}}$ & $-0.29^{\mathrm{a}}$ & ns & ns & ns \\
\hline$\Phi_{\text {PSII }}$ & $0.52^{\mathrm{c}}$ & ns & $0.37^{\mathrm{b}}$ & ns \\
\hline NPQ & $-0.36^{\mathrm{b}}$ & ns & $-0.33^{\mathrm{b}}$ & $-0.23^{\mathrm{a}}$ \\
\hline $\mathrm{q}_{\mathrm{N}}$ & $-0.30^{\mathrm{b}}$ & ns & $-0.41^{\mathrm{b}}$ & $-0.23^{\mathrm{a}}$ \\
\hline ETR 160 & $0.54^{\mathrm{c}}$ & ns & $0.37^{\mathrm{b}}$ & ns \\
\hline $\mathrm{lk}$ & $0.34^{b}$ & ns & ns & ns \\
\hline $\mathrm{ETR}_{\max }$ & $0.36^{\mathrm{b}}$ & ns & $0.29^{\mathrm{a}}$ & ns \\
\hline $\mathrm{R}_{\mathrm{fd}}$ & $0.31^{\mathrm{b}}$ & ns & ns & ns \\
\hline
\end{tabular}

stress. Stomatal effects, undoubtedly, played a crucial role in the limitation of photosynthesis in the plant adaptation to water stress, however, the average values of STI for the gas-exchange parameters did not differ under SD and SAD conditions (Table 1). Probably, the differences in the biomass tolerance, characteristic of the studied plants undergoing water stress of various intensity, were conditioned by nonstomatal effects, and, in particular, by the differences in the efficiency of the defense response at the cellular level. We observed considerable differences in the total Car content (Table 1). Although we did not address this question specifically, we can suppose that the increase in the Car content observed under SD conditions was provided both by primary and secondary Car. Positive correlations of STI for Car with STI for $\mathrm{F}_{\mathrm{v}} / \mathrm{F}_{0}$ and $\mathrm{F}_{\mathrm{v}} /$ $\mathrm{F}_{\mathrm{m}}$ are illustrative of the important role the primary Car play supporting PA functions (Table 3). Along with that, a considerable amount of secondary Car is known to be accumulated in many phototrophic organisms under the influence of unfavourable conditions, including drought (Boussiba 2000). As Solovchenko and Neverov (2017) indicate, secondary Car are very resistant molecules. Once they appear, they remain in the cell for a long time, increasing its tolerance by (1) optical shielding of the cell from excessive PAR, (2) providing the sink of excessive photosynthates, (3) by consumption of $\mathrm{O}_{2}$ and (4) due to a local antioxidant effect. These attributes of the secondary Car are very important for the adaptation observed in our experiments to long-term water stress. However, under more severe conditions combining soil and atmospheric water stress, there was no increase in the Car content, which can probably be explained by failures in the mechanisms of Car synthesis.

Unlike much data concerning decrease in the $\mathrm{Chl}$ content in leaves of wheat and other plants (Keyvan 2010, Nikolaeva et al. 2010, Chen et al. 2015, Li et al. 2017, Pour-Aboughadareh et al. 2017) under water stress, we observed the increase in $\mathrm{Chl} a$ and $\mathrm{Chl} b$ under unfavourable conditions. This can be both related to the increase in the $\mathrm{Chl}$ molecule concentration per unit mass of a desiccated leaf and the phenomenon 'stay-green' when PA damage is partially or fully prevented during the leaf-ageing period (Thomas and Howarth 2000). Genetic and physiological reasons for the 'stay-green' effect are diverse; in particular, Rivero et al. (2007, 2009) showed that the increased cytokinin production delayed the senescence of transgenic tobacco leaves induced by drought. Presumably, the increased Chl content, which we observed under SD conditions, was 'functional staygreen', as the $\mathrm{Chl}$ content tolerance positively correlated with the one of the $\mathrm{Chl}$ fluorescence parameters and biomass (Table 3). Under SAD, STI for the biomass did not correlate with STI for Chl, while the correlations between the tolerance of the photosynthetic parameters and the one of the pigment content were negative (Table 2). We believe that this is related to the 'non-functional stay-green' state, when leaves remain green due to the disturbance of Chl catabolism, but the photosynthetic ability is reduced, probably because of the unfavourable modifications of pigment-protein complexes under the influence of water stress (Thomas and Howarth 2000). The genetic background for 'stay-green' is well studied for rice (Jiang et al. 2004), wheat (Kumar et al. 2010), and another crop plant species (Thomas and Howarth 2000). The ability of CS/Syn RILs to maintain the high $\mathrm{Chl}$ content under conditions of water stress presumably has a genetic background. As we observed earlier, both in the parental genotypes of selection variety Chinese Spring, the habitat of which belongs to the southern regions of China, and in the ones of the synthetic hexaploid Synthetic 6x, obtained by means of hybridisation of wild ancestors of wheat species Triticum dicoccoides and Aegilops tauschii (McFadden and Sears 1946), the Chl content per unit fresh 
leaf mass increased under conditions of drought (Osipova et al. 2016).

In all the RILs, both under SD and SAD conditions, the ratio $\mathrm{F}_{\mathrm{m}} / \mathrm{F}_{0}$ fluctuated around $4, \mathrm{~F}_{\mathrm{v}} / \mathrm{F}_{\mathrm{m}}$ fluctuated around 0.8, which meant that PSII was well preserved (Goltsev et al. 2016).

Among the parameters of $\mathrm{Chl}$ fluorescence, $\mathrm{F}_{\mathrm{v}} / \mathrm{F}_{\mathrm{m}}$, $\mathrm{F}_{\mathrm{m}} / \mathrm{F}_{0}$, and $\mathrm{F}_{\mathrm{v}} / \mathrm{F}_{0}$ were the most stable ones, which is consistent with the data provided by M. Zivcak et al. $(2008,2013)$ for winter wheat as well as with the data published by Lichtenthaler et al. (2005). We observed a significant increase in STI for $\mathrm{F}_{0}$ in RILs only under SAD conditions, which was indicative of a relative tolerance of the excitation energy transfer processes in the lightharvesting antenna of PSII in wheat.

In our experiments, the parameters of the fast light curve based on $\mathrm{Chl}$ fluorescence were the most sensitive to the intensity of water stress. In particular, they concerned lk and ETR $_{\max }$, their STI tended to increase proportionally to the level of the stress. At the same time, average STI values for NPQ and $\mathrm{q}_{\mathrm{N}}$ were less than 1 regardless of growing conditions; as in most RILs (under SAD, 85\%; under $\mathrm{SD}, 75 \%$ ), NPQ and $\mathrm{q}_{\mathrm{N}}$ values were lower under stress conditions. In the experiments carried out by Zivcak et al. (2013) with winter wheat leaves (Triticum aestivum L.) to different drought conditions, an increase in NPQ took place when the water stress reached the critical level and the stomata were almost fully closed. The threshold level of $g_{\mathrm{s}}$, where NPQ significantly increased, was about $0.12 \mathrm{mmol} \mathrm{m}^{-2} \mathrm{~s}^{-1}$. In our experiments, the average value of $g_{\mathrm{s}}$ under SD was $0.041 \mathrm{~mol} \mathrm{~m}^{-2} \mathrm{~s}^{-1}$ with the range of variation $0.01-0.09 \mathrm{~mol} \mathrm{~m} \mathrm{~m}^{-2} \mathrm{~s}^{-1}$; under $\mathrm{SAD}$, it was $0.029 \mathrm{~mol} \mathrm{~m}^{-2} \mathrm{~s}^{-1}$ with the range of variation $0.01-0.05 \mathrm{~mol}$ $\mathrm{m}^{-2} \mathrm{~s}^{-1}$. Apparently, under conditions of our experiments, most RILs did not reach the threshold level of $g_{\mathrm{s}}$, which could influence the increase in NPQ. It was as very likely that under water stress, the decrease in nonphotochemical quenching of Chl fluorescence and the increase in $\mathrm{ETR}_{\max }$ were related to the 'stay-green' phenomenon, as a result of which the cyclic electron transport enhanced around PSII and PSI.

It is to be noted that STI for $\mathrm{ETR}_{160}, \mathrm{k}$, and $\mathrm{ETR}_{\max }$ positively correlated with $\mathrm{STI}$ for $\mathrm{R}_{\mathrm{fd}}$ under soil-drought conditions, and negatively under soil-atmospheric-drought conditions. As $\mathrm{R}_{\mathrm{fd}}$ reflected the interaction of the lightdependent photosynthetic reactions with the reactions of the dark phase (Goltsev et al. 2016), it was obvious that, under SAD, the imbalance of photosynthetic regulatory mechanisms as well as the enhancement of cyclic electron flow around PSII and PSI took place, which was also highlighted in the experiments performed by Zivcak et al. (2013). Under greenhouse conditions, in addition to the soil-atmospheric water stress, there were natural fluctuations in light, which had a considerable influence on the efficiency of photosynthesis and the phenotype of plants (Vialet-Chabrand et al. 2017).

The water-water cycle is one of the alternative electron sinks and a powerful mechanism that protects the photosynthetic apparatus from damage by active forms of oxygen under stress conditions, including drought
(Foyer and Shigeoka 2011, Ivanov 2014). The positive correlations between STI for the activity of the enzymes of the water-water cycles and STI for biomass, $P_{\mathrm{N}}$, and $\Phi_{\mathrm{PSII}}$ (Table 4) indicate the important role of the water-water cycle in the stability of the photosynthetic apparatus in CS/ Syn RILs.

Conclusion: Our research identified a high tolerance of PA in leaves from CS/Syn RILs to water stress. The results showed that changes in the studied photosynthetic parameters during the adaptation of RILs to water deficiency depended on the degree of stress; under different conditions, different protective mechanisms are effective. So, the carotenoid response was found only under SD. At the same time, some unusual reactions to water stress were found: the increase in the $\mathrm{Chl}$ content and the decrease in the parameters of nonphotochemical fluorescence quenching. The chlorophyll fluorescence parameters, $F_{v} / F_{m}, F_{m} / F_{0}$, and $F_{v} / F_{0}$, which are often used to assess the physiological state of plants (Goltsev et al. 2016), were constant in our experiments and did not reflect changes in the plant status. The parameters of the fast light curve based on chlorophyll fluorescence, $1 \mathrm{k}$ and $\mathrm{ETR}_{\max }$, were the most sensitive to water supply conditions; these parameters were increasing proportionally to the stress level. In general, it seems that the cyclic transport of electrons around PSII and PSI, as well as the electron sink into the water-water cycle, were the main protective mechanisms of the photosynthetic apparatus of wheat. This conclusion is in line with the findings of Zivcak et al. (2013).

\section{References}

Ali M.B., El-Sadek A.N.: Evaluation of drought tolerance indices for wheat (Triticum aestivum L.) under irrigated and rainfed conditions. - Commun. Biometry Crop Sci. 11: 77-89, 2016.

Ashraf M., Harris P.J.C.: Photosynthesis under stressful environments: An overview. - Photosynthetica 51: 163-190, 2013.

Baier M., Noctor G., Foyer C. et al.: Antisense suppression of 2-cysteine peroxiredoxin in Arabidopsis specifically enhances the activities and expression of enzymes associated with ascorbate metabolism but not glutathione metabolism. - Plant Physiol. 124: 823-832, 2000.

Boussiba S.: Carotenogenesis in the green alga Haematococcus pluvialis: cellular physiology and stress response. - Physiol. Plant. 108: 111-117, 2000.

Chaves M.M., Flexas J., Pinheiro C.: Photosynthesis under drought and salt stress: regulation mechanisms from whole plant to cell. - Ann. Bot.-London 103: 551-560, 2009.

Chen D., Wang S., Cao B. et al.: Genotypic variation in growth and physiological response to drought stress and re-watering reveals the critical role of recovery in drought adaptation in maize seedlings. - Front. Plant Sci. 6: 1241, 2015.

Cicevan R., Hassan M., Sestras A.F.: Screening for drought tolerance in cultivars of the ornamental genus Tagetes (Asteraceae). - PeerJ. 4: e2133, 2016.

de Lamotte F., Vianey-Liaud N., Duviau M. et al.: Glutathione reductase in wheat grain. 1. Isolation and characterization. $-\mathrm{J}$. Agric. Food Chem. 48: 4978-4983, 2000.

Fernandez G.C.J.: Effective selection criteria for assessing plant stress tolerance. - In: Kuo C.G. (ed.): Adaptation of Vegetables and other Food Crops in Temperature and Water Stress. Proceedings of International Symposium. 13-18 
August 1992, Shantana, Taiwan, China. Publication nr. 93410. Pp. 531. Asian Vegetable Research and Development Center, Taipei, China.

Foyer C.H., Shigeoka S.: Understanding oxidative stress and antioxidant functions to enhance photosynthesis. - Plant Physiol. 155: 93-100, 2011.

Giannopolitis C.N., Ries S.K.: Superoxide dismutase. 1. Occurrence in higher plants. - Plant Physiol. 59: 309-314, 1977.

Goltsev V.N., Kalaji H.M., Paunov M. et al.: Variable chlorophyll fluorescence and its use for assessing physiological condition of plant photosynthetic apparatus. - Russ. J. Plant Physl+63: 869-893, 2016.

Ivanov B.N.: Role of ascorbic acid in photosynthesis. Biochemistry (Moscow), 79: 282-289, 2014.

Jiang G.H., He Y.Q., Xu C.G.: The genetic basis of stay-green in rice analyzed in a population of doubled haploid lines derived from an indica by japonica cross. - Theor. Appl. Genet. 108: 688-698, 2004.

Kalaji H.M., Schansker G., Brestic M. et al.: Frenquently asked questions about chlorophyll fluorescence, the sequel. Photosynth. Res. 132: 13-66, 2017.

Keyvan S.: The effects of drought stress on yield, relative water content, proline, soluble carbohydrates and chlorophyll of bread wheat cultivars. - J. Anim. Plant Sci. 8: 1051-1060, 2010.

Kumar U., Joshi A.K., Kumari M. et al.: Identification of QTLs for stay green trait in wheat (Triticum aestivum L.) in the 'Chirya 3' $\times$ 'Sonalika' population. - Euphytica 174: 437-445, 2010.

Lazár D.: Parameters of photosynthetic energy partitioning. - J. Plant Physiol. 175: 131-147, 2015.

Lichtenthaler H.K., Buschmann C., Knapp M.: How to correctly determine the different chlorophyll fluorescence parameters and the chlorophyll fluorescence decrease ratio $\mathrm{R}_{\mathrm{Fd}}$ of leaves with the PAM fluorometer. - Photosynthetica 43: 379-393, 2005.

Li Y.P., Li Y.Y., Li D.Y. et al.: Photosynthetic response of tetraploid and hexaploid wheat to water stress. - Photosynthetica 55: 454-466, 2017.

Liu W.J., Yuan N.H., Zhang T. et al.: Effect of water stress on photosystem 2 in two wheat cultivars. - Biol. Plantarum 50: 597-602, 2006.

Lonbani M., Arzani A.: Morpho-physiological traits associated with terminal drought stress tolerance in triticale and wheat. Agron. Res. 9: 315-329, 2011.

Mathobo R., Marais D., Steyn J. M.: The effect of drought stress on yield, leaf gaseous exchange and chlorophyll fluorescence of dry beans (Phaseolus vulgaris L.). - Agr. Water Manage. 180: 118-125, 2017.

McFadden E.S., Sears E.R.: The origin of Triticum spelta and its free-threshing hexaploid relative. - J. Hered. 37: 81-89, 1946.

Naghavi M.R., Aboughadareh A.P., Khalili M.: Evaluation of drought tolerance indices for screening some of corn (Zea mays L.) cultivars under environmental conditions. - Not. Sci. Biol. 5: 388-393, 2013.

Nakano Y., Asada K.: Hydrogen peroxide is scavenged by ascorbate-specific peroxidase in spinach chloroplasts. - Plant Cell Physiol. 22: 867-880, 1981.

Nikolaeva M.K., Maevskaya S.N., Shugaev A.G. et al.: Effect of drought on chlorophyll content and antioxidant enzyme activities in leaves of three wheat cultivars varying in productivity. - Russ. J. Plant Physl+ 57: 87-95, 2010.

Osipova S., Permyakov A., Permyakova M. et al.: Regions of the bread wheat $\mathrm{D}$ genome associated with variation in key photosynthesis traits and shoot biomass under both well watered and water deficient conditions. - J. Appl. Genet. 57: 151-163, 2016.

Permyakova M.D., Permyakov A.V., Osipova S.V. et al.: Chromosome regions associated with the activity of lipoxygenase in the genome D of Triticum aestivum L. under water deficit. Russ. J. Plant Physl+ 64: 28-40, 2017.

Pestsova E.C., Börner A., Röder M.S.: Development and QTL assessment of Triticum aestivum-Aegilops tauschii introgression lines. - Theor. Appl. Genet. 112: 634-647, 2006.

Pour-Aboughadareh A., Ahmadi J., Mehrabi A.A. et al.: Physiological responses to drought stress in wild relatives of wheat: implications for wheat improvement. - Acta Physiol. Plant. 39:106, 2017.

Rivero R.M., Kojima M., Gepstein M.: Delayed leaf senescence induces extreme drought tolerance in a flowering plant. $-\mathrm{P}$. Natl. Acad. Sci. USA 104: 19631-19636, 2007.

Rivero R.M., Shulaev V., Blumwald E.: Cytokinin-dependent photorespiration and the protection of photosynthesis during water deficit. - Plant Physiol. 150: 1530-1540, 2009.

Solovchenko A., Neverov K.: Carotenogenic response in photosynthetic organisms: a colorful story. - Photosynth. Res. 133: 31-47, 2017.

Thomas H., Howarth C.J.: Five ways to stay green. - J. Exp. Bot. 51 (S1): 329-337, 2000.

Vialet-Chabrand S., Matthews J.S.A., Simkin A.J. et al.: Importance of fluctuations in light on plant photosynthetic acclimation. - Plant Physiol. 173: 2163-2179, 2017.

Wang X., Wang L., Shangguan Z.: Leaf gas exchange and fluorescence of two winter wheat varieties in response to drought stress and nitrogen supply. - PLoS ONE 11: e0165733, 2016.

Wettstein D.: [Chlorophyll lethal and the submicroscopic change of plastids.] - Exp. Cell Res. 12: 427-506, 1957. [In German]

Zivcak M., Brestic M., Olsovska K. et al.: Performance index as a sensitive indicator of water stress in Triticum aestivum. Plant Soil Environ. 54: 133-139, 2008.

Zivcak M., Brestic M., Balatova Z. et al.: Photosynthetic electron transport and specific photoprotective responses in wheat leaves under drought stress. - Photosynth. Res. 117: 529-546, 2013.

(C) The authors. This is an open access article distributed under the terms of the Creative Commons BY-NC-ND Licence. 